\title{
A CONSTRUÇÃO DO SUS E A PARTICIPAÇÃO DO ASSISTENTE SOCIAL
}

\author{
Fernanda de Oliveira Sarreta ${ }^{1}$ \\ Iris Fenner Bertani ${ }^{2}$
}

\section{RESUMO}

O artigo analisa os desafios na construção e implementação do Sistema Único de Saúde (SUS), que se dá num contexto em que as políticas sociais são orientadas pelos ideais neoliberais, de caráter restritivo e de privatização, e a saúde é tratada segundo a lógica do mercado, ferindo os princípios e as diretrizes constitucionais. A participação do assistente social no processo de construção e desenvolvimento do SUS, busca fortalecer a perspectiva da universalização do acesso aos programas e políticas sociais. A profissão vem produzindo conhecimentos e alternativas para enfrentar as dificuldades vivenciadas no cotidiano, provocando o alargamento do trabalho na área da saúde pública.

PALAVRAS-CHAVE: Política de Saúde; Serviço Social; Projeto Profissional

\section{INTRODUÇÃO}

A Constituição Federal de 1988 configura-se um marco na história da sociedade brasileira, na medida em que define garantias individuais e coletivas e estabelece um sistema de Seguridade Social abrangente, assegurando direitos universais de acesso à saúde, previdência e assistência social. Nela, a saúde é certificada como "um direito de todos e dever do Estado", e as ações e serviços públicos passam a integrar uma rede regionalizada e hierarquizada, constituindo o Sistema Único de Saúde

\footnotetext{
1 Doutora em Serviço Social pela Universidade Estadual Paulista - UNESP, Campus de Franca. Professora da Faculdade de Serviço Social de Passos - FESP/UEMG, e da Faculdade de Direito FAFRAM. Pesquisadora do Grupo QUAVISSS. Assistente social da Prefeitura Municipal de Franca na área da saúde. Email: fersarreta2009@yahoo.com.br.

${ }^{2}$ Livre Docente do Curso de Graduação e do Programa de Pós-Graduação em Serviço Social da UNESP, Campus de Franca. Coordenadora do QUAVISSS - Grupo de Estudos e Pesquisas sobre Saúde, Qualidade de Vida e Relações de Trabalho da UNESP, Campus de Franca. E-mail: irisbertani1311@yahoo.com.br.
} 
(SUS), organizado com diretrizes de descentralização, integralidade e participação (BRASIL, 1988).

A criação do SUS representou, no final dos anos de 1980, uma mudança significativa de caráter institucional. A organização da atenção à saúde no Brasil, durante os anos de 1990, provocou grandes inovações decorrentes do processo de descentralização, refletindo na busca de soluções relacionadas à oferta de ações e serviços de saúde em termos nacionais e no âmbito regional e municipal. No entanto, apesar deste direcionamento da política de saúde, o fortalecimento da política econômica neoliberal manteve a continuidade das desigualdades no acesso aos bens e serviços públicos, como a saúde. A crise econômica e sociocultural, intensificada nos anos oitenta, somada às mudanças econômicas e políticas de ordem mundial na década de 1990 e início do século XXI, chocou-se com os direitos afirmados constitucionalmente. Estes acontecimentos causaram uma filosofia dissonante aos direitos sociais e trabalhistas garantidos legalmente, mas distanciados no plano prático, tendo como consequências rebatimentos no modo de reprodução material de vida.

O SUS enfrenta problemas que envolvem o acesso e a qualidade do atendimento, e comprometem o modelo de atenção proposto e sua legitimidade. Desde sua criação e os primeiros esforços de implantação, há o imperativo de efetivar a mudança do modelo de atenção, na execução dos novos paradigmas apontados. Esta necessidade tem sido constantemente apontada nos espaços coletivos de debates, como conferências, congressos, seminários, de onde se dirigem moções aos órgãos públicos de saúde para adequar o atendimento e a qualidade dos serviços prestados nessa direção.

Embora a consolidação desta política pública, e sua avançada proposta de reforçar a participação da sociedade e a descentralização dos serviços apresentam-se como um novo caminho para se construir a saúde, observa-se que as formas de Revista Serviço Social \& Saúde. UNICAMP Campinas, v. X, n. 11, Jul. 2011 
encaminhar as questões no cotidiano reproduzem o modelo de atenção curativa e as práticas centralizadoras e autoritárias (SARRETA; BERTANI, 2005). Os problemas enfrentados apontam os limites das iniciativas públicas voltadas à implantação definitiva do conceito ampliado de saúde, ainda não bem elaborado e compreendido pelos sujeitos envolvidos nesta área, e pela sociedade em geral. Sobretudo, esse esforço de ruptura e superação do modelo curativo não se realiza de forma simplista, representa em si uma quebra dos paradigmas tradicionais da saúde.

Referindo-se às forças da sociedade, para uma mobilização reformista de implantação efetiva desta política, cabe refletir sobre a adesão dos atores da saúde como protagonistas. Dentre esses, o mais vulnerável e que tem sido constantemente vitimizado, como objeto de um atendimento precário em suas doenças, tem sido o usuário. $\mathrm{O}$ bombardeio constante da mídia em geral consolida a opinião pública de que só se sujeitam ao atendimento do SUS aqueles que, em decorrência da pobreza e fracasso social, não conseguiram dar um passo a mais na escada social, destinada aos mais hábeis e preparados (BERTANI; SARRETA; LOURENÇO, 2008).

Assim, não se trata apenas do desconhecimento da proposta do SUS, mas principalmente de uma profunda e arraigada descrença no inespecífico setor público, infelizmente confirmado quase diariamente pelos fatos. A ideia social deste sistema de saúde, por partir do pressuposto da universalidade de acesso e da atenção integral da saúde como direito, surge como conflitante ao modo de viver e de produção predominante hoje na sociedade capitalista: desigual, individualista e excludente. O entendimento costuma frequentemente ser ligado às condições de custo-benefício na aplicação de recursos, esquecendo-se situações comunitárias de base cultural e da própria forma de gestão local. Pode-se cogitar que, se o SUS encontra-se ainda muito afastado de sua realização, esta incompletude talvez se deva a fatores relacionados com 
as formas de envolvimento dos sujeitos sociais e de aspectos resultantes de decisões que não satisfazem propriamente os anseios da população.

Neste cenário, o Serviço Social brasileiro tem uma participação ativa e efetiva na defesa do direito social à saúde e do Sistema Único de Saúde (SUS) como política pública do Estado, universal e integral. A implantação do SUS e seu desenvolvimento no país vêm requerendo a atuação do assistente social no processo de gestão da saúde, atuando na (re)organização de serviços, planejamento, execução e avaliação de programas e políticas, no controle social, entre outras demandas que expressam a abrangência do conceito de saúde vigente. Especialmente nos municípios, onde se realiza efetivamente o trabalho e se concretizam as ações de saúde, buscando fortalecer a perspectiva da universalização do acesso a bens e serviços relativos às políticas sociais (BRAVO, 2006).

A profissão vem produzindo conhecimentos e experiências para o enfrentamento dos desafios vivenciados nesta área, provocando o alargamento da prática profissional, que, associada à produção de conhecimentos e à qualificação profissional, vem legitimando o trabalho e ampliando as possibilidades de acesso e de inclusão social. Sobretudo, o Serviço Social se sobressai no endosso ao reconhecimento dos fatores condicionantes e determinantes da saúde da população - trabalho, renda, alimentação, moradia, educação, saneamento básico, acesso aos bens e serviços essenciais, como expressões da questão social (SARRETA; BERTANI, 2006).

São avanços relacionados ao compromisso da categoria profissional na busca de qualidade do trabalho, na produção teórico-científica, além do mais no endosso ao reconhecimento de que a saúde, em seu sentido mais abrangente, é a resultante das condições de vida e de trabalho da população (BRASIL, 1988). É deste modo, o resultado de organização social da produção, as quais podem gerar grandes Revista Serviço Social \& Saúde. UNICAMP Campinas, v. X, n. 11, Jul. 2011 
desigualdades nos níveis de vida. Estes avanços demonstram que a profissão vem buscando estratégias inovadoras para enfrentar os desafios e dar respostas qualificadas no desenvolvimento do trabalho e, ao mesmo tempo, vem fortalecendo e ampliando o debate e as reflexões do exercício profissional na sociedade contemporânea, tendo como referência o projeto ético-político profissional.

\section{A CONSTRUÇÃO COLETIVA DO SUS}

O movimento da Reforma Sanitária brasileira, que transcorreu as décadas de 1970 e 1980, procura viabilizar a construção da saúde como direito da população e dever do Estado, apresentando a cidadania como um componente central e a descentralização do processo decisório como caminho para a democratização do poder local, através de novos mecanismos de gestão (BRAVO, 1996). Como analisa a autora, em outro estudo, esse movimento é significativo e “[...] consiste na organização dos setores progressistas de profissionais de saúde pública, que colocou em debate a relação da prática em saúde com a estrutura de classes" (2004, p. 32), e busca o fortalecimento do setor público em oposição.

Há neste contexto, a formulação de propostas para o setor, relacionadas aos problemas emergentes no país - desemprego, saúde restrita a alguns, falta de saneamento básico, habitação, infraestrutura inadequada - resultantes do processo acelerado da industrialização, urbanização, imigração, empobrecimento, desemprego, entre outros problemas. Neste percurso, a realização da $8^{\mathrm{a}}$ Conferência Nacional de Saúde em 1986, marca um novo momento para a saúde pública no Brasil. Com expressiva participação popular de 4500 pessoas, sendo 1000 delegados representantes de diversos setores da sociedade civil, delibera propostas para pressionar a Assembleia Nacional Constituinte e inserir o projeto defendido pelos movimentos sociais na 
Constituição brasileira (BRAVO, 1996). Esta organização demonstra que este passo foi decisivo para o processo de concretização de direito à saúde e de atribuições e responsabilidades entre os níveis de governo - federal, estadual e municipal.

Considerada um marco na história da saúde pública brasileira, a $8^{\mathrm{a}}$ Conferência Nacional de Saúde consagra as ideias preconizadas neste movimento, assinalando um processo democrático, quando sistematiza e formaliza como proposta política as principais teses discutidas para a Reforma Sanitária brasileira, envolvendo o conceito abrangente de saúde. Foi nesta Conferência que as diretrizes e os princípios do SUS são formulados e organizados como uma política pública do Estado brasileiro (BRASIL, 2006).

Portanto, este processo resultou que a saúde foi definida na Constituição Federal, como elemento da Seguridade Social (BRASIL, 1988, p. 103), a qual “[...] compreende um conjunto integrado de ações de iniciativa dos Poderes Públicos e da sociedade, destinados a assegurar os direitos relativos à saúde, à previdência e à assistência social [...]", com objetivos de universalidade, uniformidade, equidade, descentralização, entre outros. Esses objetivos levam Bravo (1996, p. 9) a considerar que a Seguridade Social é:

[...] a corporificação legal e institucional de um acordo societário que se construiu como base de nosso processo de transição à democracia. Em outras sociedades latino-americanas, com uma experiência democrática muito mais densa, a transição teve o caráter de reconstrução da institucionalidade democrática. No caso brasileiro, dada a escassa e frágil experiência democrática anterior, a transição constituiu-se no momento de criação dos instrumentos e processos democráticos. Nunca a noção de cidadania e de direitos sociais havia sido tão discutida e vivenciada em nossa sociedade. 
O direito à saúde, descrito na Constituição, no Artigo 196, é “[...] garantido mediante políticas sociais e econômicas que visem à redução do risco de doença e de outros agravos e ao acesso universal e igualitário às ações e serviços para sua promoção, proteção e recuperação" (BRASIL, 1988). É deste contexto que emergem significativas mudanças, tendo como maior exemplo, o conceito saúde, entendido até então como a ausência de doenças e um bem-estar físico e mental, é ampliado em seus diversos fatores determinantes e condicionantes das condições de vida e de trabalho da população com intenção de alterar a situação de desigualdade na assistência à saúde. Ou seja:

A saúde tem como fatores determinantes e condicionantes, entre outros, a alimentação, a moradia, o saneamento básico, o meio ambiente, o trabalho, a renda, a educação, o transporte, o lazer e o acesso aos bens e serviços essenciais; os níveis de saúde da população expressam a organização social e econômica do País. Parágrafo único. Dizem respeito também à saúde as ações que, por força do disposto no artigo anterior, se destinam a garantir às pessoas e à coletividade condições de bem-estar físico, mental e social (BRASIL, 1990, p. 20).

Esta concepção integral de saúde prevê que as ações devam ser desenvolvidas sobre o ambiente e os indivíduos, destinadas à proteção, promoção e recuperação, para erradicação das causas sociais que interferem na saúde. Portanto, a história evidencia que o SUS foi conquistado com trabalho, luta, com a mobilização da sociedade, apontando a influência da população na gestão da saúde e na direção dos interesses da coletividade (SARRETA, 2010). Não obstante, as conquistas institucionais aprovadas não conseguiram romper com a lógica anterior, onde a base de financiamento e funcionamento do sistema de proteção social esteve sempre atrelada ao capital privado. 
Para Cohn (1997, p. 234), o sistema de Seguridade Social instituído - saúde, previdência e assistência social - " [...] ao mesmo tempo que universaliza os direitos sociais, segmenta os distintos setores da sociedade no acesso a benefícios e serviçoo". A autora enfatiza que, ao mesmo tempo em que o setor privado se estruturou e capitalizou nas décadas de 1960 e 1970, atualmente pressiona e busca novos mercados de serviços prestados à Seguridade Social sem intervenção estatal. Ainda nesse pensamento, o movimento sanitário brasileiro termina a década de 1980 “[...] assistindo ao seu esgotamento - representado pela mudança institucional do setor - sem, no entanto, lograr reverter a lógica que vinha regendo as políticas de saúde de maneira a garantir a universalidade e a equidade da atenção à saúde num processo de crescente exclusão social"' (COHN, 1997, p. 235).

É este contexto que vai interferir, de forma negativa, no desenvolvimento do SUS. As mudanças profundas da economia brasileira, desde a década de 1980, provocadas pelo processo de "globalização" do mercado e pelo novo paradigma tecnológico de produção levaram a um "[...] desenvolvimento industrial com alto grau de transnacionalização" (COHN, 1997, p. 236). Em consequência, o país enfrenta a década de 1990 com o custo social profundo e com iniciativas de privatização do patrimônio estatal e de várias de suas responsabilidades. "Neste caso a contrapartida do capitalismo selvagem traduz-se numa privatização selvagem", conclui Cohn (1997, p. 236).

A ideologia do neoliberalismo, que informa as políticas econômicas e sociais nas últimas décadas, tem rejeitado a responsabilidade do Estado perante as novas expressões da questão social. Assim, contemporaneamente, as políticas sociais como mecanismos de regulação da questão social não desapareceram - reestruturaram-se para responder aos desafios impostos pelas transformações societárias, no nível econômico, Revista Serviço Social \& Saúde. UNICAMP Campinas, v. X, n. 11, Jul. 2011 
político, cultural, social. Só que esta reestruturação comprometeu um projeto de sociedade que tinha referência na igualdade, o que exige, na análise de Pereira (2000), determinação e preparo intelectual e político para lutar pela prevalência dos valores de uma sociedade justa, livre e igualitária.

Para exemplificar esta situação, as últimas décadas no Brasil evidenciaram o agravamento da pobreza e dos níveis de desigualdades e das precárias condições de vida. De acordo com dados do Instituto Brasileiro de Geografia e Estatística (IBGE), na década de 1990 apenas $10 \%$ da população detinha 51,5\% da renda nacional, em contrapartida os $10 \%$ mais pobres detinham apenas $0,7 \%$ (BRAVO, 2006). O que se observa é a mercantilização da vida determinada pela conjuntura econômica, onde o poder do mercado fortalece cada vez mais a hegemonia do capital. Esse movimento repercute na saúde e confronta diretamente com as propostas do SUS e, do mesmo modo, contribuiu para a transformação dos espaços políticos em espaços de mercantilização: onde tudo tem preço e compra quem pode.

A perspectiva é a de fortalecer as propostas nascidas no movimento da Reforma Sanitária brasileira e que constituem as ideias centrais do SUS, especialmente porque concentram as necessidades e expectativas da sociedade em relação à saúde. Na idéia defendida por Campos (2007), é na concepção ampliada de saúde, que considera as condições de vida e de trabalho e relaciona saúde aos fatores que a determinam - as condições materiais de vida, que deve pautar a luta pelo sistema público de saúde.

Deste modo, a partir do SUS, tem-se a compreensão de saúde não mais enquadrada apenas nos limites da doença. Há o enfoque, sobretudo, dos determinantes sociais, embora no cotidiano ainda sobressaiam ações embutidas de antigos valores. $\mathrm{Na}$ realidade, os serviços de atenção primária, mais próximos dos usuários e da sua realidade, deveriam enfocar a promoção da saúde, contudo, acabam se restringindo à 
execução de tarefas dentro da lógica do capitalismo. Portanto, observa-se que apesar dos avanços postos pela mudança de paradigma da política de saúde, os atendimentos continuam sendo feitos dentro do modelo verticalizado tradicional, sem que haja qualquer manifestação de visão de mundo sócio histórica. E, observa-se ainda, que o enfrentamento desses problemas não é somente econômico, mas são também culturais, políticos, sociais e principalmente, educativos (SARRETA; BERTANI, 2005).

Buscando soluções para questões tão complexas, encontram-se na reflexão de Campos (2006) alguns caminhos possíveis para a consolidação do SUS. O autor reflete que há um desencantamento da população brasileira em relação ao SUS, quanto à viabilidade de uma política social que é solidária e racional. Assim, qualquer movimento que faz de melhora não repercute, e a população não reconhece as conquistas, em razão das situações apresentadas nos serviços de saúde. Esse desencantamento, para Campos (2006), está relacionado à própria Reforma Sanitária que está incompleta e apresenta vários sintomas, sendo necessário repensar sua prática. E, lembra que hoje, no mundo comandado pelo modelo neoliberal, um sistema de saúde com princípio universal está na contramão deste processo social. Desse modo, a recuperação da imagem da política pública de saúde, exige dos sujeitos sociais uma ação que estimule os movimentos sociais e as opiniões em defesa da vida, do bem estar e da proteção social.

Outro aspecto, ao analisar o funcionamento do SUS, os serviços de saúde sobrevivem ao modelo de gestão caracterizado, diz Santos (2008, p. 4), por “[...] drástico sub-financiamento público, fragmentação dos repasses federais, largo predomínio do pagamento de serviços por produção em regra com valores inferiores aos custos, descolamento dos hospitais do SUS das redes hierarquizadas/regionalizadas". O autor associa a baixa implementação dessas redes de atendimento, com a precarização 
das relações de trabalho na prestação dos serviços, e ausência de práticas de metas, desempenho e resultados. Enfim, enquanto o país privilegiar o setor privado, como sendo o principal e o público complementar, nenhum recurso será suficiente.

Destaca-se que a reação da sociedade brasileira na busca de seu espaço legítimo na área da saúde se deu por meio do processo participativo e estratégias mobilizadas por ocasião da Reforma Sanitária e construção do SUS (BRASIL, 2006). A adoção dessas propostas pela Constituição de 1988 e Lei Orgânica da Saúde (BRASIL, 1990), como política pública do Estado, foram efetivadas por meio de políticas e programas complementares. Toda sua elaboração visava à aproximação das medidas de saúde à população brasileira, como um direito.

A saúde vista de modo isolado, inviabiliza a luta por sua efetivação com qualidade, como se pode perceber pelo afastamento da temática das reivindicações políticas e da descrença generalizada na própria força da temática no embate social. Na realidade, a política de saúde se encontra nos assuntos de maior relevância das campanhas eleitorais, objetivada nas mais diferentes ideologias. Contudo, a sua materialização prática no dia-a-dia dos serviços está pautada pelo descaso político, e pode ser verificado na falta de incentivo e esclarecimentos sobre o SUS, acrescentada pela falta de incentivo e pelos baixos salários pagos aos funcionários da saúde (BERTANI; SARRETA; LOURENÇO, 2008).

Esses fatores tornaram o serviço público prestado sem muita importância, resistindo contra a falta de recursos, em condições de trabalho precárias e cobranças sociais elevadas. Como nenhum dos componentes motivacionais acontece, completa-se o quadro de carências: o atendimento do SUS torna-se um serviço prestado de baixa qualidade, distanciando o aspecto integrado e integrador da $8^{\text {a }}$ Conferência Nacional de Saúde para a Reforma Sanitária. Há o enfoque, sobretudo, dos determinantes sociais, 
embora no cotidiano ainda sobressaiam ações embutidas de antigos valores, e os atendimentos continuam sendo realizados dentro do modelo verticalizado tradicional, sem que haja qualquer manifestação de visão de mundo sócio histórica. Algumas características desse antigo modelo de saúde pública se desdobram na dependência da dinâmica dos serviços técnico-administrativos e burocráticos institucionais, que tanto podem interrompê-los como perpetuá-los.

As atribuições estabelecidas, bem como as introduzidas na direção da responsabilidade sanitária, indicam que a atenção em saúde abrange a prevenção e promoção, ocorrendo nas condições e processos de trabalho. As respostas dadas pela instituição do SUS às demandas de saúde-doença remetem necessariamente às determinações da questão social e das transformações contemporâneas, bem como ao papel do Estado e da sociedade na sua condução e gestão.

As constantes críticas e o questionamento persistente do projeto de Reforma Sanitária tem resultado na articulação do mercado, com vistas a estabelecer um modelo de política de saúde conhecido pela característica privatista. A partir do receituário neoliberal os recursos públicos são racionalizados, vulnerabilizando a efetiva universalização e a qualidade do acesso a saúde, não consolidando seu bem mais precioso, a construção de uma nova consciência sanitária e política (CAMPOS, 2007).

Enfatiza-se que a adoção do projeto neoliberal pelo Estado brasileiro acaba provocando um distanciamento entre as medidas de proteção social garantidas no texto legal e as que vêm sendo praticadas. Nas palavras de Iamamoto (2006, p. 188) “[...] subordina os direitos sociais à lógica orçamentária, a política social à política econômica, em especial às dotações orçamentárias e, no Brasil, subverte o preceito constitucional". Ao discutir o que chama de subversão dos direitos sociais, Iamamoto (2006, p. 188) aponta para a inversão das regras, ou seja, “[...] ao invés do direito Revista Serviço Social \& Saúde. UNICAMP Campinas, v. X, n. 11, Jul. 2011 
constitucional impor e orientar a distribuição das verbas orçamentárias, o dever legal passa a ser submetido à disponibilidade de recursos". A autora mostra ainda no mesmo texto, que as prioridades dos gastos públicos na viabilização dos direitos sociais são reféns " [...] do balanço entre crédito e déficit no 'cofre governamental', estabelecida pelo bloco do poder (2006, p. 192)".

O núcleo temático mais importante das políticas sociais na vertente neoliberal é o afastamento do Estado de suas responsabilidades sociais, implicando em retrocessos da cidadania tanto no plano legal quanto no prático, uma vez que acaba ocorrendo a sua restrição e não a sua ampliação. A discussão de Pereira (2006, p. 109) acerca dos conceitos de cidadania e justiça social analisa o efeito do impacto neoliberal nas suas condições de efetivação, e argumenta que "[...] sob o neoliberalismo, mais do que nunca ficou claro que os direitos de cidadania são de fato direitos dos ricos em um mundo repleto de pobres".

A área da saúde, apesar do compromisso com os ideais da Reforma Sanitária, ao implantar as políticas de modo fragmentado, perpetua a falta de integração entre os conteúdos propostos enquanto nega os saberes, desejos e experiências acumuladas pelos sujeitos sociais nesta área. A política de saúde vincula-se aos processos econômicos, políticos, culturais e ideológicos, portanto, a sua constituição enquanto prática social relaciona-se ao modo de desenvolvimento social do país.

Esse momento atual, de repensar a prática do SUS, em razão das situações apresentadas nos serviços oferecidos, é indispensável para que a sociedade brasileira reconheça o SUS como um projeto em construção; um modelo de atendimento que traz em sua constituição a ideia de cidadania e de justiça social, a ser implantado em uma sociedade injusta e desigual. Abranger a amplitude de sua cobertura é fundamental para a consolidação plena, o que não se dará espontaneamente: exige a participação e uma 
vigilância constante em defesa dos direitos sociais tão duramente conquistados (SARRETA; BERTANI, 2005).

Entender saúde condicionada e, assim intrinsecamente, determinada pelas condições de "[...] moradia, saneamento básico, meio ambiente, trabalho, renda, educação, transporte, lazer, e o acesso a bens e serviços essenciais" (BRASIL, 1990, p.1), implica na decisão do investimento político em um bem social, que por sua profundidade nos resultados e pela amplitude da abrangência na vida da população pode ser considerada um bem maior, a saúde. Esta ausência de priorização na sociedade ocorre, frequentemente, sem que qualquer debate tenha sido realizado e os determinantes sociais da saúde tenham sido exigidos com ênfase na população.

Na verdade essa ideia construída da política pública de saúde é portadora de um projeto socioeconômico para a sociedade incluindo a saúde: um SUS pobre para os $80 \%$ de pobres, de baixo custo e de pouca resolutividade, focalizado nesta população, e simultaneamente complementar para os $20 \%$ que consomem planos privados de saúde, com foco nos bens e serviços mais especializados e de maior custo, passando por um festival de terceirizações e desvios de demanda para o mercado (SARRETA, 2010).

Campos (2006) destaca que o SUS apresenta uma nova configuração para o desenho da saúde pública brasileira, em especial pela ampliação da descentralização. Mas, como o próprio autor mostra em outro estudo, o viés dado pelo modelo ainda não assumiu integralmente os princípios constitucionais, uma vez que permanecem hegemônicos em nossa sociedade “[...] restos do antigo modo de organizar a atenção, [...] centrado em hospitais, especialistas, com pequeno grau de coordenação e de planejamento da assistência" (CAMPOS, 2007, p. 303).

Para que ocorra de fato a incorporação dos determinantes sociais e econômicos no processo de saúde-doença, é necessário pensar na formação e Revista Serviço Social \& Saúde. UNICAMP Campinas, v. X, n. 11, Jul. 2011 
desenvolvimento de novas práticas e saberes (SARRETA; BERTANI, 2005). Trata-se de um movimento que passa pela objetivação do trabalho no interior do SUS, determinado pelas condições objetivas postas pelas exigências da demanda e das novas práticas. O desafio mais persistente para a implantação do SUS passa a ser, então, a integralidade, como forma de evitar que o sistema de saúde pública constitua-se de programas focais voltados aos menos favorecidos.

O modelo de atenção prevalecente no Brasil, ainda, é voltado para as condições agudas e não atende as necessidades de saúde. É preciso pensar a integralidade da atenção, como um conjunto de valores que movem a ação na saúde, e o ponto central desses valores é reconhecer o direito de todos de terem acesso às tecnologias disponíveis. A sociedade brasileira ampliou o conceito de saúde, isso significa pensar que a integralidade da atenção é o grau de conhecimento que a sociedade tem dos seus direitos, e como ela é tratada na esfera estatal, para assim, apropriar como cidadão do direito à saúde.

Desse modo, o Brasil tem grandes desafios, apresenta 53 milhões de pessoas vivendo abaixo da linha da pobreza, com 1 real/dia por indivíduo, e 90\% dos recursos mundiais na saúde são consumidos por apenas 10\% da população (CONASSS, 2006). Outro aspecto nesse quadro, apresentado pela OPAS/OMS na América Latina, uma análise de 1995 a 2004, mostrou que a saúde na região depara-se com vários desafios e as reformas do Estado não trouxeram melhoria na qualidade de vida das populações: "Na região, 27\% dos habitantes não têm serviços básicos de saúde permanentes, e 17\% dos recém-nascidos não recebem assistência prestada por pessoal qualificado" (OMS, 2007). Enfim, é preciso enfrentar esses desafios para superar as dificuldades apresentadas na saúde, e um destes desafios é construir reformas sociais efetivas, 
solidárias e participativas, seguindo as proposições da Reforma Sanitária brasileira, para superar as contradições políticas no SUS.

Importa realçar que as referências para a mudança do modelo de atenção, foram enunciadas na Declaração de Alma-Ata (OMS, 1978) e posteriormente na Carta de Ottawa (BRASIL, 2002). Este novo paradigma aponta a estratégia da atenção primária à saúde, na direção de uma abordagem diferenciada, a fim de extrapolar a atenção centrada na doença e realçar a importância dos fatores condicionantes e determinantes da saúde. Um paradigma que enfoca a prevenção e promoção da saúde na direção da autonomia das pessoas, da participação da comunidade, do meio ambiente sustentável e a utilização de tecnologia acessível todos os governos, como caminhos para atingir qualidade de vida. Nesta referência, a organização e funcionamento do sistema de saúde estabelecem uma postura de planejamento voltado para a autorresponsabilidade e a participação de todos os setores e campos de atividade associada ao desenvolvimento nacional e comunitário (STARFIELD, 2002).

O direcionamento das políticas públicas saudáveis e a criação de ambientes favoráveis à saúde, associados à reorientação do sistema de saúde no paradigma da promoção da saúde, é um caminho que aponta para a diminuição das iniquidades na saúde, enraizada nas desigualdades existentes na sociedade (BRASIL, 2002). Para superá-las requer políticas públicas que busquem incrementar o acesso das pessoas a bens e serviços promotores de saúde, estabelecendo-se alta prioridade aos grupos mais desprivilegiados e vulneráveis, como indica o próprio Ministério da Saúde (2002), quanto aos cuidados primários, um aspecto vital para a equidade em saúde. Isso demonstra que a busca de soluções e a construção de parcerias intersetoriais são, portanto, alternativas para identificar interesses comuns e resolver problemas, influenciando positivamente na participação ativa das pessoas, nas alterações das Revista Serviço Social \& Saúde. UNICAMP Campinas, v. X, n. 11, Jul. 2011 
condições sanitárias e na maneira de viver, constituindo uma cultura de saúde (RAVAGNANI; SARRETA, 2008).

\section{O SERVIÇO SOCIAL NO CENÁRIO DO SUS}

O Serviço Social brasileiro apresenta um projeto profissional construído e legitimado pelo debate da categoria, contemplando o pluralismo como um elemento fundamental tanto da sociedade quanto do exercício profissional para sua consolidação. O projeto tem o reconhecimento da liberdade como valor central, como possibilidade de escolha entre alternativas concretas, daí o compromisso com a autonomia e a emancipação dos sujeitos (NETTO, 1999).

Os valores, ideias, opções, éticas e políticas, que caracterizam o projeto profissional, assinalam o compromisso com os interesses e as necessidades da classe trabalhadora brasileira, portanto, para Netto (1999) antagônico ao projeto defensor do neoliberalismo que vem promovendo a redução dos direitos sociais, a privatização do Estado, o sucateamento dos serviços públicos, o enxugamento do papel do Estado, a redução das políticas sociais. As consequências deste processo na vida social é o desemprego, a exclusão social, o aprofundamento das desigualdades provocado pela concentração da riqueza e da renda, e consequentemente de desproteção social.

O desempenho profissional, assim como os aportes teóricos, metodológicos e ideológico está marcado pela busca de uma referência para subsidiar a análise da realidade considerando sua historicidade. Isto autorizou à profissão constituir uma interlocução com as ciências sociais e outras áreas do conhecimento (NETTO, 1999). A formação generalista possibilita, portanto, apreender as expressões da questão social com uma base teórico-metodológica direcionada à compreensão dos processos 
relacionados à realidade brasileira, contexto onde se gestam as políticas sociais, inclusive a da saúde.

As proposições enunciadas no projeto ético-político do Serviço Social, materializadas no Código de Ética profissional de 1993, estão articuladas ao projeto da Reforma Sanitária brasileira, visando efetivar a universalidade do acesso à saúde, por meio de políticas públicas efetivas. Para Bravo e Matos (2004) são projetos que enunciam princípios e diretrizes para a construção de relações democráticas, com base na liberdade e participação ativa dos sujeitos sociais, na perspectiva do desenvolvimento da autonomia e emancipação dos sujeitos, de ruptura com práticas autoritárias, centralizadoras e assistencialistas.

Ao estudar as profissões da saúde, Bravo e Matos (2004, p. 56) afirmam que o Código de Ética do assistente social "[...] encontra-se em sintonia com as garantias constitucionais, na defesa de princípios e valores de ordem humanística, libertária, democrática e igualitária”. Para os autores, os avanços alcançados no Serviço Social têm como base o debate do direcionamento ético-político que vincula a profissão a um projeto societário que propõe a construção de uma nova sociedade, mais justa, sem exploração e sem dominação, opções que reafirmam a defesa dos direitos humanos. Outro aspecto, a ser destacado, é o reconhecimento da categoria profissional aos usuários dos serviços de saúde como sujeitos protagonistas (VASCONCELOS, 2002).

A política pública de saúde é o setor que, historicamente, mais tem absorvido profissionais de Serviço Social: "[...] a quarta maior categoria no âmbito do SUS" (BRAVO, 2006, p. 39). O reconhecimento do assistente social como integrante da equipe de saúde vem-se construindo através da inserção nas políticas de saúde desde o seu surgimento, apresentando-se, hoje, amplamente inserido nos serviços e programas de saúde. Para Martinelli (2000) esta relação é constitutiva na construção da identidade 
profissional, fortalecida na defesa do direito social e, assim, “[...] é uma profissão necessária numa perspectiva interdisciplinar, pois contribui para que a equipe de saúde desenvolva ações que considerem as necessidades da população" (2000, p. 56).

O assistente social dispõe de atribuições específicas na área da saúde (CFESS, 1999), qualificando o profissional para atuar com competência nas diferentes dimensões da questão social no âmbito das políticas sociais, inclusive da saúde. As atribuições constituem um instrumento importante na construção de estratégias para o exercício profissional e a busca de alternativas efetivas visando o atendimento das necessidades sociais apresentadas pelos usuários nos serviços de saúde. Estão pautadas no conceito de saúde inscrito na Constituição, na formação profissional generalista e no compromisso ético-político anunciado no Código de Ética da profissão, que reafirma o seu posicionamento em favor da equidade e da justiça social, que assegure universalidade de acesso relativo às ações e serviço, bem como sua gestão democrática.

As atribuições ressaltam a perspectiva interdisciplinar para a atenção integral, juntamente com ações intersetoriais e comunitárias que se aproximem do cotidiano da população e ampliem o conhecimento da realidade local e regional (SARRETA, 2008). O desenvolvimento de estratégias programadas em equipe possibilita a compreensão da saúde pela sociedade como direito e questão de cidadania, e fortalece o paradigma que considera a saúde um elemento central da organização e desenvolvimento social, econômico e político do país. Ao valorizar a perspectiva interdisciplinar e intersetorial nas relações de trabalho, a fim de garantir a atenção às necessidades da população, na mediação de seus interesses e a prestação de serviços e, ao desenvolver atividades profissionais específicas - plantão, entrevista, avaliação sócio-econômica, assistência material, trabalho com grupos, visitas domiciliares entre outras - o assistente social ajuda a população a ter acesso à saúde (SILVA; SARRETA; BERTANI, 2007). 
Isto pode ser observado em diversos aspectos referenciados no projeto éticopolítico profissional. Um destes aspectos acontece pela facilidade de acesso do usuário ao assistente social nas unidades de saúde, no acolhimento, na escuta diferenciada, na divulgação e informação de ações e serviços de saúde e dos programas desenvolvidos pelo profissional. Outro aspecto é o desenvolvimento da capacidade de identificação das demandas no âmbito da saúde, e de extrair destas demandas as reais necessidades sociais e de saúde, apontando a formulação e execução de políticas sociais, projetos e programas, como um direito (RAVAGNANI; SARRETA, 2008).

Nesta referência, o assistente social insere-se no processo de trabalho da saúde atuando na construção de estratégias que busquem criar experiências e aproximar as ações desenvolvidas no SUS com as demais políticas sociais. O desenvolvimento de estratégias programadas em equipe possibilita a compreensão da saúde pela sociedade como direito e questão de cidadania. Ao reconhecer a saúde como resultado das condições econômicas, políticas, sociais e culturais, o Serviço Social passa a fazer parte do conjunto de profissões necessárias à identificação e análise dos fatores que intervém no processo saúde-doença.

É desta perspectiva, que o trabalho do assistente social na área da saúde, que busca o enfrentamento das expressões da questão social na saúde visando o atendimento das necessidades apresentadas pelos usuários, para Bravo e Matos (2004, p. 17), e que “[...] queira ter como norte o Projeto Ético-Político deve, necessariamente, estar articulado ao Projeto da Reforma Sanitária”. Portanto, é na referência destes projetos que a profissão pode fornecer subsídios para que o usuário se fortaleça e participe do controle social na saúde, ampliando assim, “[...] os canais de interferência da população na coisa pública, de modo a permitir maior controle por parte da sociedade nas decisões que lhes dizem respeito" (IAMAMOTO, 2006, p. 126). 
São procedimentos significativos no cotidiano, que se aperfeiçoam pela busca do conhecimento e do aprimoramento técnico-operativo e teórico-metodológico com vista ao fortalecimento do trabalho. São funções e respostas que a profissão vai desenvolvendo, a partir das condições apresentadas pela população, que acabam influenciando as demandas institucionais e legitimam o projeto profissional na superação da situação atual (IAMAMOTO, 2006). É nesta intencionalidade de superação das desigualdades e injustiças sociais que está posta a capacidade de transformação.

Ao imprimir uma postura investigativa no trabalho, o assistente social fortalece a atividade profissional determinada e influenciada pela realidade social. E, ao valorizar a atividade científica por meio da pesquisa (GUERRA, 2009), gera dados ligados às condições de vida da população, à reprodução das relações sociais, à implementação das políticas sociais. As informações de experiências desenvolvidas e socializadas podem contribuir na elaboração de propostas mais apropriadas às necessidades sociais.

A amplitude deste processo alcança-se com observação constante e registro sistemático dos aspectos da realidade que se manifestam por meio dos processos sociais, na organização do conhecimento dado pela experiência, tornando-o mais legítimo. Ao mesmo tempo, transforma o exercício profissional e valoriza seu significado junto às demandas sociais, buscando estratégias que atualizam, revitalizam e redirecionam o trabalho. A reflexão crítica realimenta a própria condição do trabalho, contribui para desenvolver o potencial criativo e a capacidade de transformar seu direcionamento, (ALMEIDA, 2006; MARSIGLIA, 2006).

A adoção destes elementos nas experiências vivenciadas pode contribuir para que os profissionais desenvolvam seu potencial criativo e a capacidade de transformar o 
direcionamento do trabalho. $\mathrm{O}$ aprofundamento científico, sobre os determinantes do trabalho profissional e dos instrumentos próprios da profissão, ajuda na elaboração de propostas mais apropriadas às necessidades sociais. A oportunidade de experimentar novos caminhos para a autonomia no exercício profissional pode dimensionar também o trabalho do assistente social no SUS, ao adotar atitudes no cotidiano para exercitar a prática contínua de documentação do trabalho, planejamento em equipe, visando ao desenvolvimento de ações e programas para a inclusão social dos usuários.

A organização de um plano de trabalho como subsídio, que compreenda as etapas e conteúdos do processo científico (objetivos, metodologia, resultados alcançados e avaliação), o estudo e elaboração do instrumental e procedimentos adequados à realidade e local de trabalho, é uma alternativa para ampliar a ação e desenvolver formas de atuação efetiva nos Conselhos de Direitos, como espaço legítimo que favorece o controle social dentro do SUS. A formação e qualificação profissional permanente para atualização e fortalecimento do referencial teórico-metodológico e instrumentalização da análise e da intervenção na realidade social torna-se uma necessidade pontual. Realiza-se como um processo de ação-reflexão-ação acerca dos limites, dos avanços e da contribuição efetiva da profissão na área da saúde imprimindolhe maior visibilidade institucional e social.

\section{CONSIDERAÇÕES FINAIS}

O exercício profissional fundamentado na perspectiva apresentada, de direitos e interesses coletivos, envolve uma dimensão política, ética e técnica, na busca de alternativas para contribuir com o processo de democratização dos serviços públicos. Entretanto, o projeto ético-político do Serviço Social não se defende apenas com argumento teórico, pois é nas relações estabelecidas que ele se materializa. É na postura 
dialogada, como um caminho promissor para refletir as questões acerca da realidade social, que a profissão busca respostas para materializar os princípios e diretrizes do projeto profissional e do projeto da Reforma Sanitária brasileira.

Na reflexão de Iamamoto (2006), as possibilidades são dadas na realidade, mas não são automaticamente transformadas em alternativas profissionais. Cabe aos assistentes sociais apropriarem-se dessas possibilidades e, como sujeitos transformá-las em projetos de trabalho. A prática educativa é inerente à atividade profissional do assistente social, que acumula experiências na dinamização de ambientes coletivos, na realização de grupos, na democratização dos espaços institucionais e, como subsídio que fortalece o controle social, a participação e a construção do processo democrático dentro dos serviços de saúde. Contudo, na prática educativa a instrumentalização política e intelectual dos sujeitos envolvidos na saúde não garante sua emancipação, já que solicita que seja reflexiva, participativa, direcionada para a autonomia.

Esta perspectiva no exercício profissional significa contribuir no processo de fortalecer e instrumentalizar a população para o exercício de cidadania, e os próprios trabalhadores da saúde para que tenham uma nova relação com o trabalho e a própria saúde. Do mesmo modo, democratizar os serviços de saúde significa criar espaços que permitam a construção do conhecimento e da interação, para que os sujeitos possam compartilhar conhecimentos e experiências entre si e buscar respostas para os problemas que impedem o acesso à saúde. É um caminho que pode tornar possível o desenvolvimento de potencialidades e habilidades, além de estimular a capacidade de crítica, de organização e de luta pela garantia de direitos. Ao acreditar e investir no desenvolvimento dos sujeitos sociais emerge o potencial transformador sobre suas ações no mundo. 
Ressalta-se que diante das investidas do projeto neoliberal, no desmonte das conquistas historicamente construídas, torna-se necessário construir estratégias coletivas que ampliem a luta pela defesa dos direitos sociais. O direcionamento do trabalho deve possibilitar uma atuação profissional que supere o papel de reprodução e manutenção e de descompromisso com os interesses das classes trabalhadores. Daí a importância de um referencial teórico e metodológico comprometido com as necessidades sociais e os interesses coletivos, para ampliar a perspectiva ética na garantia de direitos e elevar o nível de vida da população.

Enfim, é preciso investir cotidianamente no resgate das relações sociais, que estão desumanizadas e são arquitetadas pela aspereza do individualismo e da competitividade capitalista, e que se expressam no sofrimento humano (adoecimento, doença, perdas, incertezas e dores), e na falta de perspectiva associada à precariedade na qualidade do atendimento e no desinteresse com a vida humana. E, com a mesma intensidade, é preciso acreditar no potencial que a ação crítica e reflexiva do assistente social sobre o cotidiano ajuda a produzir novas possibilidades, a explicitar interesses divergentes e apontar projetos alternativos. A busca de respostas para problemas que impedem a saúde e a qualidade de vida fundamenta-se nesta capacidade de acreditar que a realidade pode ser transformada e (re) construída, e o trabalho pode determinar novas relações e provocar impactos positivos na realidade social. 


\section{ABSTRACT}

The article examines the challenges in the construction and implementation of the Single Health System (SUS), which occurs in a context in which social policies are guided by neoliberal ideals, and restrictive nature of privatization, and health is treated according to the logic the market, injuring the principles and constitutional guidelines. The involvement of a social worker in the process of construction and development of the SUS, seeks to strengthen the prospect of universal access to programs and social policies. The profession has been producing knowledge and alternatives to face the difficulties experienced in daily life, causing enlargement of work in the area of public health.

KEYWORDS: Social Policie, Social Work, Training Project

\section{REFERÊNCIAS BIBLIOGRÁFICAS}

ALMEIDA, N.L.T. de. Retomando a temática da "sistematização da prática" em Serviço Social. In: MOTA, A. E. et al., (Orgs). Serviço Social e Saúde: formação e trabalho profissional. São Paulo: OPAS, OMS, Ministério da Saúde, 2006. p. 399 - 408.

Bertani, I. F., SARreta, F. de O., LOUREnÇO, E. A. de S. Aprendendo a construir saúde: desafios na implantação da política de educação permanente em saúde. Franca: UNESP, 2008.

BRASIL. Constituição da República Federativa do Brasil. 18. ed. São Paulo: Saraiva, 1988.

BRASIL. Ministério da Saúde. Secretaria de Gestão Estratégia em Participativa. A construção do SUS: história da reforma sanitária e do processo participativo. FALEIROS, V. P. et.al. Brasília: Ministério da Saúde, 2006. 300 p. (Série I. História da Saúde no Brasil). 
Ministério da Saúde. Lei Orgânica da Saúde de n $^{0} 8.080$ de 19 de setembro de 1990. Brasília: Ministério da Saúde, 1990.

. Ministério da Saúde. As cartas da promoção da saúde. Brasília: Ministério da Saúde, 2002.

COHN, A. Mudanças econômicas e políticas de saúde no Brasil. In: LAURELL, A.C. (Org.). Estado e políticas sociais no neoliberalismo. São Paulo: Cortez, 1997. Saúde no Brasil: políticas e organização de serviços. 6. ed. São Paulo: Cortez, 2005.

CONSELHO FEDERAL DE SERVIÇO SOCIAL. CFESS. Atribuições do assistente social na saúde. Resolução nº 383/99 de 29 de março de 1999. Brasília: CFESS, 1999. BRAVO, M. I. S. Serviço Social e reforma sanitária: lutas sociais e práticas profissionais. São Paulo: Cortez, 1996. . (Org.). Saúde e Serviço Social. São Paulo: Cortez, 2006.

; MATOS, M. C. de. Reforma Sanitária e projeto ético-político do Serviço Social: elementos para o debate. In: BRAVO, M. I. de S. et al. (Org.). Saúde e Serviço Social. São Paulo: Cortez; Rio de Janeiro: UERJ, 2004, p. 23-47.

CAMPOS. G. W. de S. Reflexões sobre a construção do Sistema Único de Saúde (SUS): um modo singular de produzir política pública. Serviço Social \& Sociedade. São Paulo: Cortez, 2006, p. 132-46. Reforma política e sanitária: a sustentabilidade do SUS em questão? In:

Ciência e Saúde Coletiva. ABRASCO. Associação Brasileira de Pós Graduação em Saúde Coletiva, volume 12, mar-abr. 2007, p. 301-06.

GUERRA, Y. A dimensão investigativa no exercício profissional. In: Serviço Social: direitos sociais e competências profissionais. CFESS/ABEPSS. Brasília, 2009. p. 10118. 
IBGE. IBGE - cidades@. Disponível em:

<http://www.ibge.gov.br/cidadesat/default.php>. Acesso em: 10 jun. 2005.

IAMAMOTO, M.V. Renovação e conservadorismo no serviço social: ensaios críticos. 7. ed. São Paulo: Cortez, 2006.

As dimensões ético-políticas e teórico-metodológicas no Serviço Social contemporâneo. In: MOTA, A.E. et al. (Orgs.) Serviço Social e Saúde: formação e trabalho profissional. São Paulo: OPAS, OMS, Ministério da Saúde, 2006.

. O Serviço Social na contemporaneidade: trabalho e formação profissional.

4. ed. São Paulo: Cortez, 2001.

MARSIGLIA, R.M.G. Orientações básicas para a pesquisa. In: MOTA, A.E. et al., (Orgs). Serviço Social e Saúde: formação e trabalho profissional. São Paulo: OPAS, OMS, Ministério da Saúde, 2006. p. 383-98.

MARTINELLI, M.L. Serviço Social: identidade e alienação. 6. ed. São Paulo: Cortez, 2000.

NETTO, J.P. A construção do projeto ético-político. In: Capacitação em Serviço Social e política social. Brasília: CFESS/ABEPSS/CEAD/UNB, 1999. Mod. I. p. 1420.

ORGANIZAÇÃO MUNDIAL DE SAÚDE (OMS); ORGANIZAÇÃO PANAMERICANA DA SAÚDE (OPAS). Declaração de Alma-Ata. Conferência internacional sobre cuidados primários de saúde. OMS/OPAS, 1978.

PEREIRA. P.A.P. Necessidades humanas: subsídios à crítica dos mínimos sociais. São Paulo: Cortez, 2000.

. Cidadania e (in)justiça social: embates teóricos e possibilidades atuais. In:

REIRE, L.M.B.; FREIRE, S.M.; CASTRO, A.T.B. Serviço Social, Política Social e 
Trabalho: desafios e perspectivas para o século XXI. São Paulo: Cortez; Rio de Janeiro: Ed. UERJ, 2006.

RAVAGNANI, C. L.; SARRETA, F. O. Humanizando as relações na saúde com experiências coletivas. Serviço Social \& Realidade. p. 361-76, 2008.

; ETO, F.; SARRETA, F. O. O Serviço Social e a promoção da saúde no contexto de saúde ampliada In: Pacto pela saúde: conversando sobre o SUS. Franca: UNESP, 2010, v.1, p. 71-90.

SANTOS, N. R. dos. Encruzilhada nos rumos do SUS: considerações. 2008.

SARRETA, F. O. Educação permanente em saúde para os trabalhadores do SUS. São Paulo: Cultura Acadêmica da Fundação UNESP, 2010, v.1. p. 252.

O trabalho do assistente social na saúde pública. Ciência et Praxis. , p. 33-40, 2008.

; BERTANI, I. F. A construção do trabalho em equipe do Serviço Social no SUS de Franca/SP. In: Interdisciplinaridade: integração entre saberes e práticas. OLIVEIRA, C. A. H. da S.; BERTANI, I. F. (Orgs). Franca: UNESP, 2006. p. 55 -78. ; _ _ . O Polo de Educação Permanente em Saúde e a construção de estratégias coletivas para a formação de trabalhadores no SUS. Serviço Social \& Realidade, v. 14, p. 177- 95, Franca, UNESP, 2005.

STARFIELD, B. Atenção primária: equilíbrio entre necessidades de saúde, serviços e tecnologia. Brasília: UNESCO / Ministério da Saúde, 2002.

VASCONCELOS, A.M. de. A prática do Serviço Social: cotidiano, formação e alternativas na área da saúde. São Paulo: Cortez, 2002. 